\title{
OS RESÍDUOS SÓLIDOS: PROPOSTA E DESENVOLVIMENTO DE JOGOS EDUCATIVOS PARA AS SERIES INICIAIS.
}

\author{
Herika Bastos de Medeiros ${ }^{1}$
}

\section{Antonio Carlos de Miranda ${ }^{2}$}

\section{Luis Gabriel Rodrigues Sousa ${ }^{3}$}

RESUMO: Esta investigação tem como objetivo trazer à tona alguns aspectos da Lei da Política Nacional de Resíduos Sólidos (PNRS, no 12.305). Ao mesmo tempo, em relação a essa temática, desenvolver um jogo computacional. Além disso, avaliar a sua adequação à sala de aula, de modo que seja um instrumento facilitador e motivador no processo ensinoaprendizagem, visando à exploração de conteúdos interdisciplinares associados à educação ambiental, enfocando como tema os resíduos sólidos.

Palavras-chave: Educação ambiental. Jogo Computacional. Resíduo Sólido.

\section{INTRODUÇÃO}

Convém destacar que o Brasil está ainda muito distante das condições adequadas em relação ao tratamento dos resíduos sólidos. O problema apresenta-se na origem do descarte do resíduo. Segundo dados do IBGE (2012), no Brasil são coletados mais de

\footnotetext{
${ }^{1}$ Mestre em Ensino da Saúde e do Ambiente (UNIPLI), Prof. da Rede Municipal de São Gonçalo e Rio de Janeiro; herikabastos@yahoo.com.br

${ }^{2}$ Doutor (UNICAMP); Prof. do Programa de Pós-graduação Stricto Sensu - UNIPLI; mirantam@ig.com.br

${ }^{3}$ Mestre em Ensino da Saúde e do Ambiente (UNIPLI), Prof. da Rede Municipal de São Gonçalo e Rede Estadual do RJ; luisgabrielrs@ibest.com.br
} 
188,8 toneladas diárias de resíduos sólidos. Grande parte desse total vai para os 2.906 lixões, já que 50,8\% dos municípios não possuem aterro sanitário ou controlado ${ }^{4}$.

Por sua vez, o relatório da Abrelpe (2012) indica que, neste ano, foram gerados quase 64 milhões de toneladas de resíduos sólidos, e o índice per capita é de $383 \mathrm{~kg} / \mathrm{ano}$. É interessante mencionar que de acordo com esse relatório, ao se comparar com 2011, houve um crescimento de 1,3\% em relação à geração de produção do lixo por habitante, esse índice representa um valor superior à taxa de $0,9 \%$ do crescimento populacional desse período. O que demonstra um incremento na geração de lixo. Já a quantidade de resíduos que deixaram de ser coletadas alcançou um valor de 6,2 milhões de toneladas. Esse número justifica-se pela falta de regras claras, em relação às responsabilidades legais e de punições.

Durante 20 anos discutiu-se a Lei da Política Nacional de Resíduos Sólidos (PNRS, n‥ 12.305) sendo aprovada em 02/08/2010. A Lei traz princípios, objetivos, e instrumentos para efetivar a PNRS. Os pressupostos dessa Lei são: não gerar o resíduo; a redução; a reutilização; o tratamento e a destinação final dos rejeitos.

Segundo o Art. 8ำ (Lei 12.305): São instrumentos da Política Nacional de Resíduos Sólidos, entre outros: Os planos de resíduos sólidos deverão ser elaborados pelo poder público: Nacional (União sob a coordenação do Ministério do Meio Ambiente), Estadual (cada estado elabora o seu plano), Municipal (pode ser elaborado um plano simplificado, para isso deve ter menos de 20.000 habitantes e não tenham empreendimento de impacto Nacional/Regional) e Gerenciamento (plano como portos, aeroportos, atividades agropecuárias, etc).

Desse modo, cada município terá de realizar o seu 'Plano Municipal de Gestão Integrada de Resíduos Sólidos', que poderá ser elaborado com o auxílio de técnicos, consultores, ONG's etc. Como cada um deles têm a sua peculiaridade, por esse motivo a Lei oferece essa autonomia

\footnotetext{
${ }^{4} \mathrm{Em} 27,7 \%$ das cidades o lixo vai para os aterros sanitários e em $22,5 \%$ delas, para os aterros controlados, de acordo com dados da Pesquisa Nacional de Saneamento Básico do Instituto Brasileiro de Geografia e Estatística (IBGE).
} 
Outro avanço da Lei de Resíduo Sólido é a 'Logística Reversa', esse princípio prevê que depois de usado alguns produtos e embalagens façam um caminho inverso, ou seja, em vez de ir para o lixo, são devolvidos aos fabricantes, distribuidores ou comerciantes, que passam a ter responsabilidades pelo seu destino.

III- A coleta seletiva, os sistemas de logística reversa e outras ferramentas relacionadas à implementação da responsabilidade compartilhada pelo ciclo de vida dos produtos (Lei no 12.305 de 2/08/2010).

Segundo Souza e Fonseca (2009), através da logística reversa ${ }^{5}$ as empresas passam a ter responsabilidade pelo retorno do produto à empresa, quer para reciclagem, seja para descarte. Este ciclo se estende, abrangendo o retorno do produto ao ponto de origem.

Uma empresa pode ter uma diminuição considerável do seu custo ao reutilizar materiais que são descartados por esse cliente final. Por sua vez, no conceito de 'responsabilidade compartilhada', pelo ciclo de vida do produto, passa a envolver outras atribuições dos fabricantes, importadores etc:

[...] devem ser definidas as atribuições individualizadas e encadeadas dos fabricantes, importadores, distribuidores e comerciantes, dos consumidores e dos titulares dos serviços públicos de limpeza urbana e manejo de resíduos sólidos.(MMA, p:10, 2010).

Vale lembrar que as formas mais comuns quanto a deposição final de resíduos sólidos são: vazadouros ou lixão, aterro controlado e aterro sanitário. A lei nํㅜ 12.305/10 estabelece o fechamento ou recuperação dos lixões até 2014, assim, os resíduos deverão ir para a reciclagem e os rejeitos para os aterros sanitários.

Os resíduos não coletados ou dispostos em locais inadequados favorecem a proliferação de vetores de doenças e podem contaminar o solo e os corpos d'água. A decomposição da matéria orgânica presente no lixo, por sua vez, origina gases associados ao efeito estufa. O acesso a coleta de lixo domiciliar constitui um

\footnotetext{
${ }^{5}$ Logística reversa é o processo de planejamento, implementação e controle do fluxo de matérias-primas, estoque, implementação e controle de fluxo de matérias-primas, estoque em processo e produtos acabados (e seu fluxo de informação) do ponto de consumo até o ponto de origem, com o objetivo de recapturar valor ou realizar um descarte (Souza e Fonseca apud Lacerda, p.30, 2009).
} 
indicador de infraestrutura, principalmente para as áreas urbanas (IBGE, p: 120, 2012).

Segundo os dados apresentados pelo IBGE, através dos 'Indicadores do Desenvolvimento Sustentável' (2012, p:129), “a coleta seletiva, a reciclagem e a compostagem do lixo orgânico ao reduzirem o volume de resíduos, contribuem de forma significativa para o equacionamento da questão da destinação final do lixo no Brasil, devendo ser fortemente incentivadas". Por outro lado, o relatório da Abrelpe (2012) aponta que:

[...] é possível perceber que o País está evoluindo a passos bastante lentos no estabelecimento de uma gestão integrada e sustentável de resíduos sólidos. Com isso, concluímos que apenas a PNRS não é suficiente para alterar práticas correntes e corrigir desvios. Os instrumentos estão disponíveis e exemplos não faltam para que as ações adequadas sejam pensadas, planejadas, implementadas e cobradas.

É importante assinalar que a educação ambiental no âmbito da Política Nacional de Resíduos Sólidos tem como objetivo

[...] o aprimoramento do conhecimento e, uma mudança de hábitos $e$ atitudes, valores e comportamento relacionados aos resíduos sólidos. As medidas a serem adotadas pelo Poder Público devem ser voltadas aos fabricantes, importadores comerciantes e distribuidores, bem como aos consumidores com enfoque diferenciado para cada público-alvo (Ministério do Meio Ambiente, p: 10, 2010).

A crise ambiental tem sido amplamente discutida em diversos aspectos da sociedade, na mídia, nas escolas, nos Congressos e passa a fazer parte do nosso cotidiano. Cabe destacar que "a educação ambiental assume cada vez mais uma função transformadora, na qual a responsabilidade dos indivíduos torna-se um objetivo essencial" (FERNANDES, 2011).

Por sua vez, de acordo com os PCN's, as atividades envolvendo meio ambiente visam:

[...] contribuir para a formação de cidadãos conscientes, aptos para decidirem e atuarem na realidade socioambiental de um modo comprometido com a vida com o bem-estar de cada um e da sociedade, local e global. Para isso, é necessário que, mais do que informações e conceitos, a escola se proponha a trabalhar com 
atitudes, formação de valores e com o ensino e a aprendizagem de habilidades e procedimentos (PCN, 1997, p: 29).

A partir dessas considerações, esta investigação tem como objetivo desenvolver um Jogo Computacional e, avaliar a sua adequação à sala de aula, de modo que seja um instrumento facilitador e motivador no processo ensino-aprendizagem, visando à exploração de conteúdos interdisciplinares associados à educação ambiental, enfocando como tema os resíduos sólidos.

A importância do lúdico é reconhecida por autores como Huizinga, Kishimoto, Jean Piaget, L. Vygotsky. Segundo Huizinga (2007), existe a presença ativa do lúdico em todos os processos culturais, como o criador de muitas das formas fundamentais da vida social. Já Kishimoto (2002) afirma que a utilização do jogo potencializa a exploração e a construção de aspectos cognitivos por contar com a motivação interna típica do lúdico. Por sua vez, Vygotsky (1984) comenta que "a cultura forma a inteligência e a brincadeira favorece a criação de situações imaginárias e reorganiza experiências vividas". Enquanto Piaget (1988), afirma que "conhecer um objeto é agir sobre ele e transformá-lo, aprendendo os mecanismos dessa transformação vinculados com as ações transformadoras".

Por outro lado, vários autores afirmam a importância do jogo computacional/lúdico como facilitador e motivador no processo ensino-aprendizagem. Segundo Macedo et al (2000), "a prática com jogos, pode resultar em importantes trocas de informações entre os participantes, contribuindo efetivamente para a aquisição de conhecimento". Conforme Zaccaron et al (2012), "o uso das tecnologias digitais na educação constitui um elemento inovador e transformador das práticas educacionais vigentes e potencializam o papel do professor"

Já os PCN's (1997), sugerem a utilização dos jogos, mas não fazem menção nem explicitam a forma, as ferramentas e/ou os aportes necessários ao seu uso na atividade pedagógica: "A possibilidade e a necessidade de jogar junto com os outros, em função do movimento dos outros, passa pela compreensão das regras e um comprometimento com elas". No entanto, é importante assinalar a criação do Programa Nacional de Tecnologia Educacional (Prolnfo) que, de alguma forma, estimula o uso da informática educativa: 


\begin{abstract}
Nas escolas publicas, a instalação de laboratórios vem sendo feita pelo Ministério da Educação (MEC), que criou o Programa Nacional de Tecnologia Educacional (Prolnfo) ${ }^{6}$,com isso cada vez mais crianças e adolescentes poderão usufruir de uma educação mais interativa por meio da informática. Outra medida adotada pelo Governo Federal é o Programa Banda Larga na Escolas (PBLE), lançado em 2008, que tem como objetivo conectar todas as escolas da rede públicas urbanas à Internet, por meio de tecnologias que propiciem qualidade, velocidade e serviços para incrementar o ensino público do país (MEDEIROS e SCHIMIGUEL, p:4, 2012).
\end{abstract}

Segundo Pietruchinski, Neto e Reinehr (2011, p. 477), "das tecnologias disponíveis na sociedade moderna, em especial os jogos, é fundamental para o trabalho educacional transformador e podem ser ferramentas capazes de contribuir efetivamente para uma educação de qualidade". Seguindo o mesmo raciocínio Fantini (2012), comenta que "as TICs surgem como ferramentas de auxílio ao professor e instrumento de aprendizagem para os alunos".

\title{
MATERIAL E MÉTODO
}

Esta investigação apresenta-se como uma pesquisa qualitativa de caráter exploratória descritiva, que tem como objetivo incentivar a participação dos educandos na exploração e avaliação de um jogo educativo, focando resíduo sólido. O cenário da pesquisa foi a Escola Municipal Alberto Torres, localizada no Município de São Gonçalo, bairro Colubandê. Os sujeitos da pesquisa: 20 alunos do $3^{\circ}$ ano do Ensino Fundamental.

$\mathrm{O}$ traçado metodológico envolveu três momentos. O primeiro momento: desenvolveram-se atividades, em sala de aula, que estão indicadas no livro didático acerca de 'resíduo sólido', em seguida, um levantamento deste tema na internet, realizado no laboratório de informática. Já no segundo momento, foi feita a aplicação e análise de um questionário aberto acerca do tema. No terceiro momento, a construção e aplicação e análise do Jogo Computacional.

\footnotetext{
${ }^{6}$ Prolnfo é um programa educacional criado pela Portaria n. 522/MEC, de 9 de abril de 1997, para promover o uso pedagógico de Tecnologias de Informática e Comunicações -TICs. (MEDEIROS e SCHIMIGUEL, p. 4, 2012).
} 
No primeiro momento, os alunos analisaram o tema 'resíduos sólidos' no livro didático, assistiram vídeos educativos e realizaram um levantamento na internet.

No segundo momento, cada aluno aplicou um questionário aberto em um morador (em geral, a mãe de um dos colegas da classe), com perguntas relativas ao descarte dos resíduos sólidos. Na primeira questão, "Você sabe que parte do resíduo gerado em sua casa pode ser reaproveitado?" , $80 \%$ respondeu que sim e $20 \%$ respondeu que não.

Separo plásticos e vidros. (relato da mãe do aluno A).

No começo separava, mas depois desisti, porque quando o caminhão chega mistura tudo de novo e aí não adianta nada. (mãe do aluno F).

Pelas falas, percebe-se que existe a concepção e o conhecimento da reciclagem pelas moradoras, mas que este processo de separação é inibido e desestimulado em razão do Município não dispor de um programa de reciclagem ao realizar a coleta do lixo.

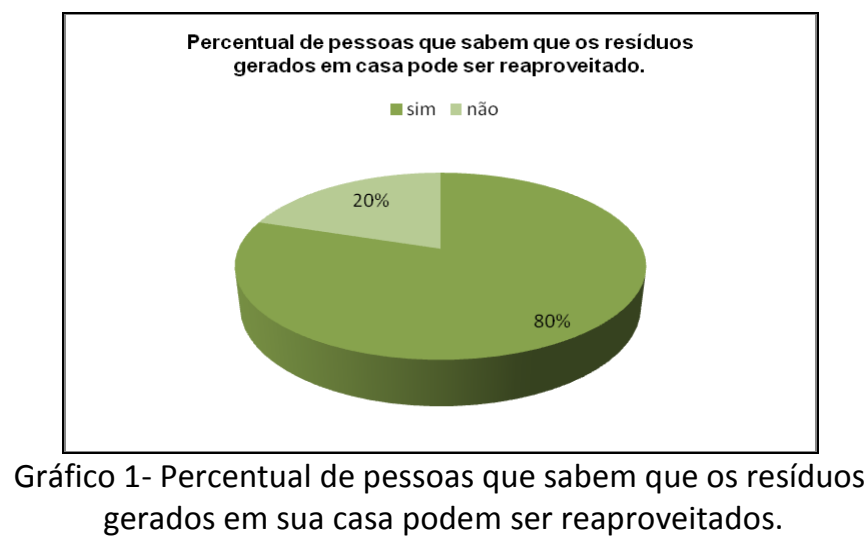

Em resposta à segunda questão, "Você costuma separar o lixo seco do molhado?", $20 \%$ responderam que sim e $80 \%$, que não. 


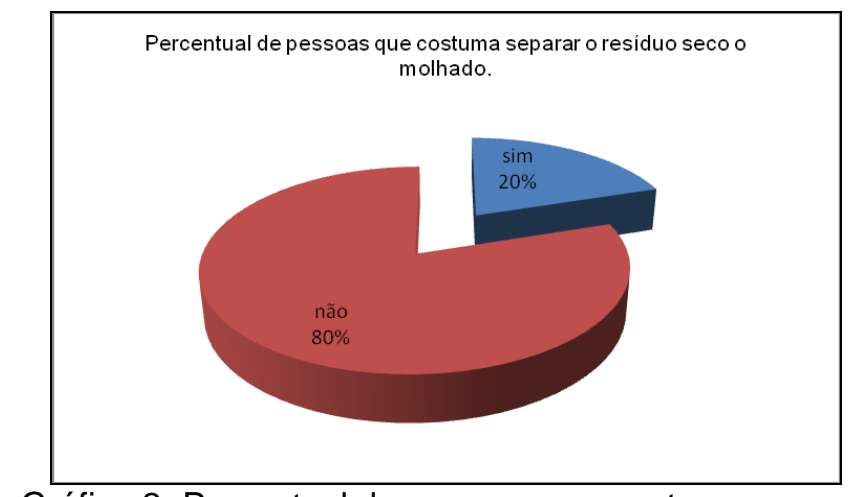

Gráfico 2- Percentual de pessoas que costuma separar

Eu separo porque fica com mau cheiro. (mãe do aluno C).

Qual a necessidade, não é tudo lixo mesmo? ( mãe do aluno E).

Eles não reciclam se o lixo tiver molhado? (mãe do aluno J).

Em resposta a terceira questão, "Que tipo(s) de resíduo(s) você acha que pode(m) ser reciclado(s)?", das vinte pessoas entrevistadas, todas concordam com a 'garrafa pet', $75 \%$ concordam com o vidro', 100\% com alumínio, $90 \%$ com plásticos, 100\% com 'pneus', $60 \%$ com bateria de celular e pilhas. Foram feitas os seguintes comentários;

Qualquer vidro é reciclado? ( mãe do aluno I).

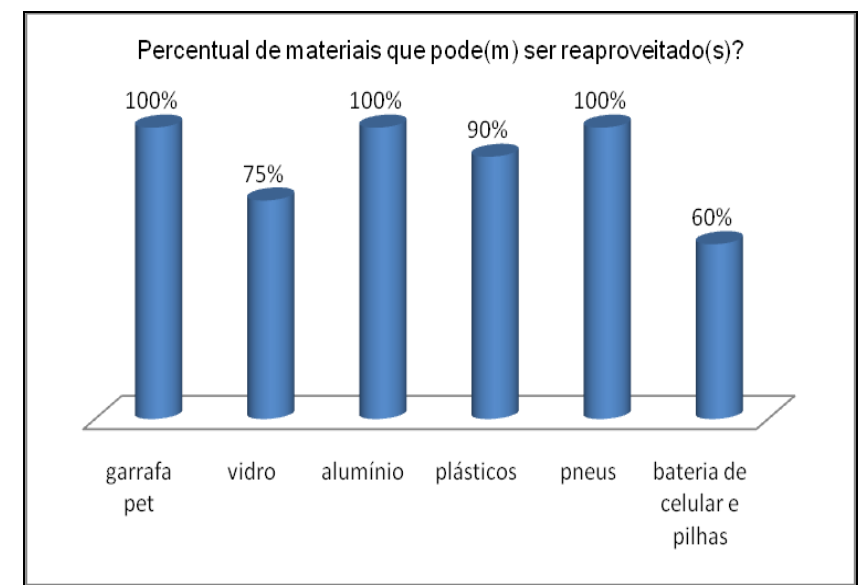

Gráfico 3- Material que pode(m) ser reciclado(s). 
As respostas confirmam que os moradores têm acesso a informação relativa à reciclagem. No entanto, como já citamos, não existe um programa do município que os motivem a fazer a separação adequada do lixo doméstico. Pelo contrário, o próprio município desestimula o morador ao não separar o lixo no momento da coleta e também por não indicar um local para que ele seja depositado voluntariamente. Esse fato demonstra a falta de apoio de implantação de um processo de reciclagem, por exemplo. Nesse sentido, acreditamos que a PNRS enfrentará muita dificuldade para alterar e romper com essas práticas correntes, em geral do próprio poder público. É importante mencionar que, pelo relatório do CEMPRE, em 2010, somente $8 \%$ dos municípios operaram programa de coletiva seletiva. Já os dados de 2011 , indicam que "apenas $5 \%$ do lixo sólido urbano gerado foi reciclado (compostado)".

\section{Construção do Jogo}

Para a construção do Jogo computacional, escolhemos o Macromedia Flash Player MX 8.0. Um programa utilizado na criação de animações interativas e aplicações, através da

linguagem voltada para objetos ActionScript. A interface gráfica do Flash 8.0 permite que mesmo usuários iniciantes possam, de maneira simples, dispor de seus recursos, mesmo sem conhecimentos sólidos de programação (MEDEIROS e MIRANDA, p: 4, 2011).

Para elaboração do jogo utilizamos o 'Template Quis', contido no Flash 8.0. Foram selecionados os seguintes frames (partes do jogo): 1- Tela de boas vindas; 2- Tela de Hot Spot (evidenciar o objeto); 3- Tela de Drag and Drop (arrastar e largar), 4- Tela de Hot Spot. 4- Tela de Pontuação.

No início do jogo o aluno terá acesso à 'tela de apresentação', onde será convidado a ter contato com o conteúdo acerca do tema 'resíduo sólido', mas jogando. Ao clicar com o mouse, na tela seguinte, é solicitado a assinalar o produto orgânico. Após marcar a imagem correta, deverá clicar no botão 'checar' que responderá: 'resposta correta' ou 'tente novamente', caso a resposta esteja incorreta. Nesse caso, o aluno terá uma nova 
chance. $\mathrm{Na}$ terceira tela, solicita-se ao aluno que arraste o lixo para a respectiva lixeira. $\mathrm{Na}$ E finalmente, ao passar para tela seguinte, terá acesso a sua pontuação de acertos.

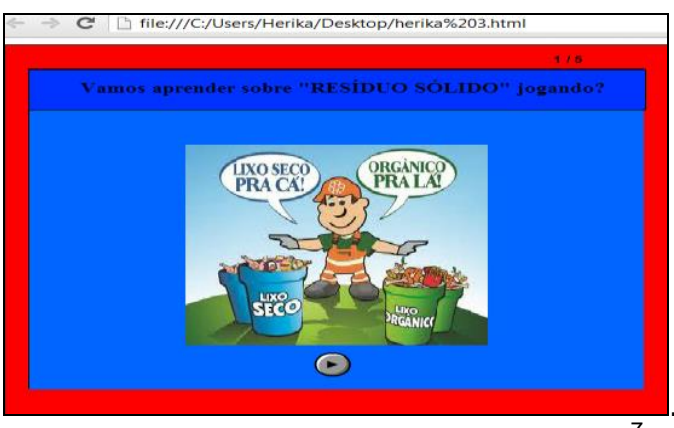

Figura 1- Tela de "boas vindas" ${ }^{7}$

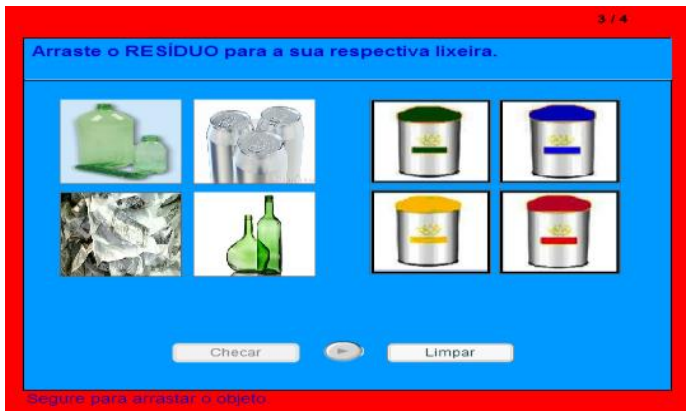

Figura 3- Tela "Drag and Drop"

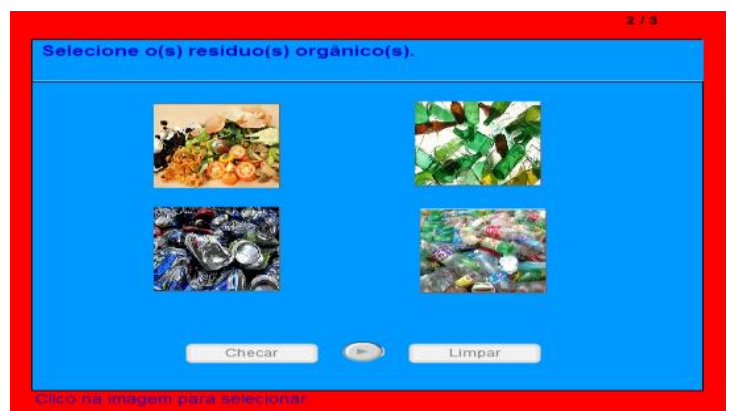

Figura 2- Tela de "Hot Spot"

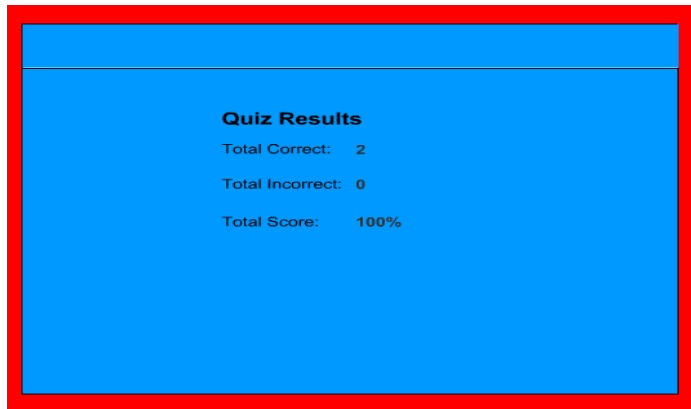

Figura 4- Tela "Score" (Pontuação)

\footnotetext{
7 As fontes utilizadas em todas as telas, respectivamente são: figura 1, fonte: http://www.garibaldi.rs.gov.br/upload/page/00166 11283359869.jpg; figura

2 ,

fontes: http://www.google.com/url?sa=D\&q=http://www.rmsoares.pt/gestao residuos reciclagem vidro.aspx\&usg=AFQjCNEGrXofW4m4Ycv4D6 YYTfY8-iZqIA; figura 3, fontes: http://radames.manosso.nom.br/ambiental/files/lixo-organico.jpg; figura 4,fontes:http://www.google.com.br/url?sa=i\&source=images\&cd=\&cad=rja\&docid=cuLQw1hZnuJlmM\&tbnid=wy3FGYVjhy8FeM:\&ved=0C AgQjRwwAA\&url=http\%3A\%2F\%2Fbalbacch14.blogspot.com\%2F\&ei=uyYtUuTILY709gSDwID4CQ\&psig=AFQjCNErnFow4yomAsNLCSfCDp1Uvt3lg\&ust=1378777147860179; figura 5, fontes: https://encrypted tbn2.gstatic.com/images?q=tbn:ANd9GcSfaaeqjqQD5MMwZaKHnJNynAXtKRB9Xv17xJVfRG-ieXxWmzjqEeYD_Zk; figura 6, fontes: http://2.bp.blogspot.com/-Hf2zmFBPc w/Tpgk8yQiBkI/AAAAAAAAABI/ 4RYaAJC064/s1600/05 0516 Brasil reciclagem.jpg; $\quad$ figura $\quad 7, \quad$ fontes: http://www.fashiondescontrol.com.br/wp-content/uploads/2012/06/papel-amassado.jpg; 


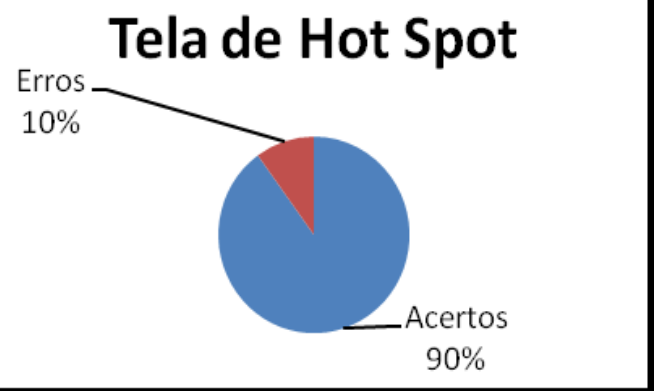

Gráfico 4-Tabulação dos resultados da tela 2

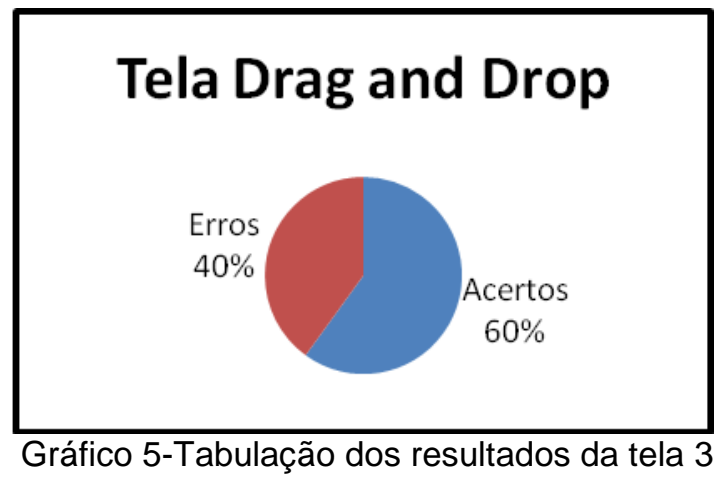

Percebemos que ouve maior motivação e interesse dos alunos, em sala de aula, a partir da utilização do jogo. No entanto, identificamos uma maior dificuldade quando responderam ao jogo: 'arraste o resíduo para sua respectiva lixeira'. Dos 20 alunos, 8 erraram, porque se confundiram com as cores das lixeiras, e dos 12 que acertaram, 5 deles só conseguiram, após a segunda tentativa. Ficou claro, por essa dificuldade, que não é comum para eles encontrarem essas lixeiras no seu cotidiano.

Conforme Fernandes apud Layargues (2011), diante de uma sociedade moderna e industrializada, a maneira simplificada de mostrar como iniciar a educação ambiental é a coleta seletiva ao invés da coleta convencional, em que vem se destacando as latas de alumínio - material mais reciclado. Cabe mencionar que a reciclagem das latas de alumínio apresenta-se como um mito, como afirma Miranda (2005, p. 53), no que tange ao seu caráter 'solucionador' ou 'salvador do planeta'. Na verdade, o motivo principal pelo qual este material é visto como campeão entre todos os materiais reciclados é a economia de energia e de custos das empresas, isto é, há um grande interesse delas neste processo. Isso é pouco divulgado e observado pela população. Nesse sentido, sempre fica a imagem de que a reciclagem apresenta-se como a 'melhor solução', assim, não fica explícito de que ela também provoca impacto ao meio ambiente e consome energia.

\section{CONSIDERAÇÕES FINAIS}

O jogo apresentou-se como uma etapa importante, no sentido de ser uma estratégia ensino aprendizagem motivadora e adequada ao abordar, em uma fase inicial, o tema 
'resíduos sólidos'. No entanto, essa é uma atividade afastada do cotidiano dos alunos e que precisa ser mais enfatizada com outras atividades. Como vimos, as respostas dos moradores apontam que não existe um programa do município que os mobilizem a fazer a separação adequada do lixo doméstico. Pelo contrário, o próprio município gera o desestímulo ao não separar o lixo no momento da coleta e, ainda, ao não indicar um local para que ele seja depositado voluntariamente. Esse fato demonstra a falta de apoio de implantação de um processo de reciclagem, por exemplo. Nesse sentido, acreditamos que a PNRS enfrentará muita dificuldade para alterar e romper com essas práticas correntes, em geral do próprio poder público. Por outro lado, a educação ambiental apresenta-se, nesse caso, como um canal importante na busca da cidadania plena, visando alcançar os direitos da população, no sentido de obter a implementação adequada da coleta de resíduos sólidos, em seu município.

\section{BIBLIOGRAFIA}

ABRELPE. Associação Brasileira de Empresas de Limpeza Pública e Resíduos Especiais.Disponível<http://www.cidadessustentaveis.org.br/sites/default/files/arquivos/pan orama residuos solidos abrelpe 2011.pdf>

MACROMEDIA Flash - Avançado com Actionscript. Disponível em http://www.baixaaqui.com.br, acessado em 20 de março de 2011.

BRASIL, Lei №. 12.305 de 2/08/2010. Institui a Política Nacional de Resíduos Sólidos. Disponível em < http://www.planalto.gov.br/ccivil_03/_ato2007-2010/2010/lei/l12305.htm>.

BRASIL, Lei nº. 9394/96- Diretrizes e Bases da Educação Nacional. LDB/MEC/SEFParametros Curriculares Nacionais para o Ensino Fundamental: Meio Ambiente e Saúde. Temas Transversais, 1aa a 4ํㅡㄹ série. 1997.

BRASIL, Ministério do Meio Ambiente. Gestão Integrada de Resíduos Sólidos. Sugestões para elaboração de Plano Municipal ou Intermunicipal de Gestão Integrada de Resíduos Sólidos (PMGIRS), Fascículo 4, 2010.

CEMPRE. Compromisso Empresarial para Reciclagem, 2010. Disponível em http://www.cempre.org.br/ 
FANTINI, V. Os jogos virtuais para a educação ambiental no ensino fundamental. Revista Educação Ambiental em Ação. №. 40, 2012.

FERNANDES, R. N. A educação que vem do lixo: um estudo do programa "Piedade sem lixo" e a formação da cidadania ambiental", Revista Educação Ambiental em Ação, №. 37, 2011.

HUIZINGA, J. Homo ludens: O jogo como elemento da cultura. São Paulo, Perspectiva, 2001.

IBGE. Indicadores de Desenvolvimento Sustentável, Estudos \& Pesquisas Informação Geográfica, Vol. 9, Brasil, 2012.

IBGE. Pesquisa Nacional de Saneamento Básico do Instituto Brasileiro de

Estatística. <http://www.brasil.gov.br/sobre/meio-ambiente/gestao-do-lixo>

KISHIMOTO, T. M. Jogos infantis: o jogo a criança e a educação. 10 edição. Petrópolis: Vozes, 1993.

MACEDO, L; PETTY, A.L; PASSOS, N. C. Aprender com Jogos e Situações-problema. Porto Alegre: Artes Médicas do Sul, 2000.

MEDEIROS, H. B.; MIRANDA, A. C. Jogos Computacionais: uma proposta interdisciplinar da educação ambiental. RENOTE- Novas Tecnologias na Educação. V. 9, №. 2, dezembro, 2011.

MEDEIROS, M. O; SCHIMIGUEL, J. Uma abordagem para avaliação de jogos educativos: ênfase no ensino fundamental. CINTED, v. 10, n. 3, dezembro, 2012.

MIRANDA, A. C.; SILVA, E.; MONTEIRO, R. A Dimensão do Mito: na cosmologia; na eduicação ambiental; na história em quadrinhos. São Paulo: Editora All Print, 2005.

PIAGET, J. Para onde vai a educação? Rio de Janeiro: José Olympio, 1988.

PIETRUCHINSKI, M. H; NETO, J.C; REINEHR, S. Os jogos educativos no contexto do SBIE: uma revisão sistemática da Literatura. Anais do XXII SBIE- XVII WIE, 2011.

SOUZA, S. F; FONSECA, S. U. L. Logística Reversa: oportunidades para redução de custos em decorrência da evolução do fator ecológico. Revista Terceiro Setor, v. 2, n. 1, 2009.

VYGOSKTY, L. S. Pensamento e linguagem. São Paulo: Martins Fontes,, 1998. 
ZACCARON, A. B. M; SOUZA M. R.S; AMARO, L.S.M.A; et al. Uso Pedagógico das

Tecnologias Digitais: do fazer ao Compreender. CINTED, v. 10, n. 3, dezembro, 2012. 